\title{
ELES (NÃO) SÃo RECICLÁVEIS
}

\author{
THEY (NOT) ARE RECYCLABE
}

Priscilla Placha Sá*

RESUMO: Este texto apresenta uma abordagem do lugar do preso na sociedade. Tratando de afastamentos e interferências, comparativamente ao problema do refugo: o preso, por isso, torna-se uma questão a ser discutível, dando ensejo a empreitadas e teorias toscas, quando atinge a sociedade estabelecida. $O$ pano de fundo passa necessariamente pela questão crucial do desperdício e do descarte como produto de uma pretensa modernidade, especialmente, por não se saber lidar com o refugo social ou urbano. Encarar o problema significa resgatar a alteridade do outro abrindo os olhos para uma dicotomia recorrente (de um lado desemprego, fome, corrupção, mortes, estupros; de outro, sexualidade feliz, pornografia, encontros privilegiados, shoppings centers, hipnóticos, drogas). É preciso (re)pensar a (re)ciclagem.

PALAVRAS-CHAVE: Alteridade. Modernidade. Preso. Sistema penal.

ABSTRACT: This paper presents an approach to the prisoner's place in society. Dealing with removal and interference, in comparison to the problem of rejects: the prisoner, for that reason, becomes an issue to be debated, giving rise to rough tasks and theories, once it reaches the established society. The background inevitably cross the crucial issue of waste and descart as a product of a supposed modernity, especially for not knowing how to cope with social or urban rejects. To face the problem means to rescue the otherness of another, opening their eyes to a recurring dichotomy (in one hand unemployment, hunger, corruption, murders, rapes; on the other hand, happy sexuality, pornography, privileged date, shopping malls, hypnotic drugs). It is necessary to (re)think the (re)cycle.

KEYWORDS: Otherness. Modernity. Prisoner. Penal system.

* Graduada em Direito pela Faculdade de Direito Curitiba. Especialista em Direito Processual Penal pela PUCPR. Mestre em Direito Econômico e Social pela PUCPR Doutoranda em Direito do Estado pela UFPR. Professora de Direito Penal na UFPR e na PUCPR. 
"O refugo é o segredo sombrio e vergonhoso de toda produção."

(BAUMAN, 2005, p. 38)

“O objetivo da produção de projetos é abrir mais espaço para o 'bem', e menos ou nenhum para 'o mal'.

É o bem que faz do mal aquilo que ele é: mal. 'O mal'é o refugo do progresso."

(BAUMAN, 2005, p. 40)

"Onde há projeto há refugo."

(BAUMAN, 2005, p. 41)

\section{NOTA INTRODUTÓRIA}

O preso não faz questão para a sociedade desde que e somente se o lugar em que se encontre esteja suficientemente afastado ou apresente a necessária segurança para que dele não se lembre. Uma rebelião, por exemplo, incita o populacho e mesmo os se dizentes doutores-no-assunto a (re)pensar o sistema prisional e o próprio sistema de justiça criminal e a dizer dele e a teorizar sobre ele, por vezes, de modo assustador. Teses das mais infundadas, frases toscas e propostas bizarras sobre as "soluções" ganham a mídia e as conversas de boteco, favorecendo o populismo penal, criando mais crimes e, portanto, mais criminosos. Parece algo com a questão do lixo urbano: enquanto se pode despejar toda a sorte de refugo para algum lugar que não se vê ou não se conhece, e a coleta é feita de modo bem eficaz, tal problema deixa de fazer (ou nunca faz) questão para a sociedade. A rejeição de municípios satélites em recebê-lo ou a saturação do aterro para onde é levado, do mesmo modo, coloca em xeque uma prática da sociedade de consumo: o descarte. Coloca no espelho dois temas de nossas vidas: a falta e o excesso. O que se faz preocupante, todavia, é que não se (re)pensa este refugo em si - como prática da modernidade - numa tentativa de (se) reciclar, de (re)incluir os descartáveis em nossas vidas, mas sim na procura de algum processo, empresa ou política que dê conta "para sempre" deste excesso e, assim, permita a desenfreada satisfação social do modelo de consumo em busca da felicidade.

Este texto, inspirado em Vidas Desperdiçadas, de Zygmunt Bauman, tem por proposta trabalhar com a questão do refugo ou lixo dos dias de hoje, quando se constata que há coisas demais, mas também pessoas demais. Por certo que, embora o enfoque a isso pudesse partir das funções do sistema penal ${ }^{1}$ e das finalidades (tanto as declaradas

1 Para considerações: Baratta; Zaffaroni (2003). Não se poderia deixar - e isso aparecerá ao longo do texto - a profusa interferência do modelo econômico e social, com a polaridade capital x trabalho, como Alessandro Baratta e Juarez Cirino dos Santos evidenciam em seus textos. Em igual sentido: MELOSSI; PAVARINI (2006), mesmo porque o início da obra de Bauman que inspira este texto fala da fantástica sensação de adquirir algo novo, e nisso nada melhor do que o modelo capitalista do consumir para incitar o desprezo e o refugo das coisas (e pessoas) que sobram. 
quanto as latentes) da pena², a pretensão é fugir ao trato dogmático e criminológico, embora reconhecendo a inegável referência e importância de tais considerações, e tentar fazê-lo sob o ponto de vista ético, servindo-se então de algum aporte psicanalítico.

O livro em referência abre-se com a história de Leônia e Aglaura, as cidades invisíveis de Ítalo Calvino; a primeira tem os leoninos ávidos pelo novo e pelo descarte; a segunda vive de suas próprias histórias repetidas, pois tem aquilo de que necessita para existir. Vidas Desperdiçadas quer contar a história da modernidade e do refugo que os leoninos produzem ao produzirem sua (nossa) própria vida.

\section{REFUGO: DO ATERRO À PRISÃO}

Se há discussões sobre o melhor trato para o lixo urbano, elas também existem em torno de um (melhor) modelo para o lixo humano, que se relaciona ao modelo de sistema penal e política criminal que se delineiam (por exemplo, em tempos de rebelião ou de fuga, mais acaloradamente) como se alheios fossem a toda a história latinoamericana. O país, assim como boa parte de seus vizinhos, ainda acolhe as políticas colonialistas e imperialistas; tudo muito agravado em um espaço de globalização e pensamento único, desembocando no eficiente sistema penal de coleta da gente que sobra, que poderia ser colocada em contêineres.

“O sistema penal fornece esses contêineres. [...] De forma explícita, o principal e talvez único propósito das prisões não é ser apenas um depósito de lixo qualquer, mas o depósito final, definitivo." (BAUMAN, 2005, p. 107).

De forma teorizada ou não, a solução do sistema penal para o refugo humano da sociedade emerge como verdadeiro bálsamo (BATISTA, 2002, p. 271-288) para todos os males humanos, que projetam toda a sua energia para justificar - muitos até mesmo pelas funções do direito penal e outros tantos pelos fins da pena - a imperiosa necessidade da sanção criminal (e que seja privativa de liberdade!); o que parece apontar para um paradoxo se essa mesma gente olha o lugar penitenciário e conclui que ele é bem pior do que se pode imaginar.

Como pano de fundo, aparece o medo como produto comunicacional e, especialmente, como produto político ${ }^{3}$, no sentido de que não se está a querer expurgá-lo,

2 Vide por todos: Cirino dos Santos (2007, p. 453/490); especialmente a análise sobre os aparentes efeitos igualitários do sistema penal e o efeito simbólico produzido no imaginário popular (em especial: p. 484/485), em que pese uma análise nos dados oficiais divulgados pelo próprio Departamento Penitenciário Nacional indicarem a preferência pelos vulneráveis do sistema, com pouca instrução formal, baixa renda e subemprego, conforme já anunciado por Albrecht (Apud CIRINO DOS SANTOS, 2007, p. 477).

3 Assim, é mais do que produto comercial; a questão do combate ao crime passa a ser excelente produto político, pois fomenta o medo oficial em que o Estado, em verdade, não pode e não quer fazer nada; a inocorrência 
senão fomentá-lo, como forma de sacramentar as atividades que trabalham com o lixo, como refugo do consumo: as coisas que se descarta e as pessoas que se descarta, considerando sua desnecessidade dado o contingente exagerado de quem nada produz, mas apenas custa ao estado, sustentando duas indústrias: a da coleta do lixo das coisas e a da coleta do lixo humano.

0 medo $^{4}$ é racional ${ }^{5}$, embora para alguns não o seja. A irracionalidade quer que alguém me dê aquilo que eu não dou para ninguém: a ideia de desimportância que eu tenho pelo outro e da maior importância de mim mesmo.

A alteridade ${ }^{6}$ (ou a perda da) é a questão central no conceito segurança, pois quando se pensa que a geração do medo vem do outro e o outro não é igual a mim, admite-se que a segurança não encontrada no meu entorno pessoal de racionalidade espraie-se para o público - segurança pública - permitindo que se faça o que desejo fazer com o outro, que posso fazer tudo com o outro (tudo que se não permite fazer comigo: cidadão).

A sociedade excludente (YOUNG, 2002; WAICQUANT, 2005; DUSSEL, 2002)

do crime é ponto para o Estado, e a ocorrência demonstra cada vez mais a astúcia e audácia do inimigo. O discurso político cria estratégias fantasiosas, por meio de conceitos retóricos, como $\langle<$ crime organizado $\rangle>$, $\langle<$ crime hediondo $>>$, $<<$ regime disciplinar diferenciado $>>$, lançando mão de recursos ilimitados, com o intuito de ofertar uma solução eficaz, em seu comportamento empresarial, como forma de exercício pragmático do poder punitivo suficiente para controle dos distúrbios sociais. "Ao contrário do caso das ameaças geradas pelo mercado aos meios de subsistência e ao bem-estar, a extensão dos perigos à segurança pessoal deve ser muito divulgada e pintada nas cores mais sombrias, de modo que a não-materialização das ameaças possa ser aplaudida como um evento extraordinário, resultado de vigilância, do cuidado e da boa vontade dos órgãos do Estado." (BAUMAN, 2005, p. 68).

4 Delineado por Zygmunt Bauman em Vidas Desperdiçadas, mas também em Medo Líquido e Confiança e Medo na Cidade. Para outras visões sobre o medo: Batista (2000, p. 187-195); Silva Sanchez (2002), ao trabalhar a sensação social de insegurança como fomentadora do medo de tudo, mas o medo do outro, afetado pela atividades dos gestores atípicos da moral e pela atividade da mídia; Beck (2002), com a questão dos medos invisíveis e a divisão dos efeitos colaterais entre quem produz e quem sofre os riscos, como relatado em sua obra, em virtude do acidente de Chernobyl. Zygmunt Bauman lembra, ainda, o 'medo cósmico', na concepção do filósofo russo Mikhail Bakhtin, em que ele se representa pela "emoção humana, demasiadamente humana, desencadeada pela magnificência imaterial e desumana do universo; o tipo de medo que precede o poder construído pelo homem e que lhe serve de alicerce, protótipo e inspiração.” (BAUMAN, 2005, p. 61).

5 A importância de um discurso racional e o resgate do ser: Lévinas (1997, p. 268-276).

6 A consciência do outro como aspecto fundamental da evolução: Lévinas (1997, p. 21-34; 263-267; 268-276).

Segurança pública não é a segurança do um, do indivíduo, mas é, então, a segurança de todos, como fruto de um discurso cauteloso e inteligente, sensível aos anseios da comunidade e com a ideia de cidadania, como exercício de respeito às liberdades públicas. Cf. (COUTINHO, 2003). 
constrói (de forma inconsciente ou não) ${ }^{8}$ um criminoso (aquele que se enquadra na forma legal do tipo que descreve o crime), um marginal (no sentido mesmo de à margem). Etiquetar os escolhidos para esta "operação de limpeza", de matriz biologicista, é laborar para atribuir o rótulo e constituir a condição de criminoso ${ }^{9}$. Não propriamente pelo que faz, mas por ser quem é.

Um olhar para o Estado do Paraná, confirma a preferência histórica por determinados sujeitos (indicada por Mathiesen e já relatada no texto oitocentista de Beccaria), na hiperbólica cifra (de quase quinze mil presos definitivos): são mais de $70 \%$ de presos, cuja educação formal não supera o ensino fundamental completo, dentre estes somam quase $15 \%$ os analfabetos completos e os funcionais; mais de $70 \%$ tem entre 18 e 29 anos de idade. A percentagem de pessoas presas por terem cometido crimes patrimoniais sem violência é superior a $30 \%$, sendo significativamente pequena a parcela de pessoas presas por crimes contra a vida e crimes sexuais, o que se poderia denominar como criminalidade violenta e que é veiculada como se fosse a regra. A manipulação de dados sustenta o discurso por mais segurança, as justificativas governamentais para dotações orçamentárias com polpudas verbas, ${ }^{10}$ e que para muitos só representa uma "brutalidade inata" e não as possibilidades de uma "vida brutalizada"11.

O Mutirão Carcerário do Conselho Nacional de Justiça, em 2010, concluiu que o Paraná tem a maior população de presos provisórios do país, que representam a mesma quantidade de pessoas que já foram condenadas. Os dados demonstram uma eficiente atuação histórica que varre para os lixões do sistema penitenciário os arruaceiros, baderneiros, vadios, pessoas que andam em bandos (os bandidos), que se comportam como bárbaros e que são sujeitos socialmente indesejáveis.

São o excedente facilmente apreensível por usarem o figurino social da delinquência e frequentarem os lugares da criminalidade. Ou mesmo por apreenderem o lugar de outsider que lhes foi dado, exibirem o rótulo e a etiqueta; assim como se faz com as coisas marcadas para a remoção. Estas pessoas não são mais tidas como mão-de-obra

8 Adiante passagem sobre o alheamento em relação ao outro e a irresponsabilidade em relação a si, na visão do ethnopsiquiatra Jurandir Freire (2001).

9 As teorias da rotulagem ou labelling approach indicam a atribuição da condição de criminoso. Para uma análise sob a perspectiva de uma interação simbólica entre a atribuição do rótulo e o aceite: Elias (2000).

${ }^{10}$ Dados obtidos no sítio oficial do Departamento Penitenciário do Estado do Paraná (http://www.depen. pr.gov.br).

${ }^{11}$ Para maiores considerações: Zaffaroni; Batista et al. (2003, p. 46) ao usarem a expressão "obra tosca da criminalidade". 
de reserva ${ }^{12}$, portanto, com algum sentido de (re)aproveitamento ou utilidade $^{13}$, mas sim como excesso, como resto (BAUMAN, 2005, p. 91).

Assim, o 'refugo humano' não pode mais ser removido para depósitos de lixo distantes e fixado firmemente fora dos limites da 'vida normal'. Precisa, assim, ser lacrado em contêineres fechados com rigor (BAUMAN, 2005, p. 107).

\section{GENTE SEM-VERGONHA}

A gente que sobra, o excedente é a vergonha em si, não aquele que fez (por não ter vergonha do que faz), mas aquele que é: a vergonha radical (LÓTMAN, 1970; CALLIGARIS, 2008, p. 179-194) de ter cometido o crime que irá pesar sobre a sua própria existência, perseguindo o seu ser.

O sujeito foi se transformando em um ser que não tem vergonha (aquela que causa rubor) dos seus atos de violência, porque não erigidos estes atos ao conceito formal de crime; ou porque não fazem questão, como se tais atos não lhe dissessem respeito; também porque - em termos de América Latina, dois fatores parecem contribuir sofisticadamente para essa prática: (i) a estratificação social (Ter x Ser), pelo fenômeno da concentração de renda, a cultura do consumo, e a exclusão social; e (ii) a notada influência católica, em que o arrependimento é sempre possível, pela infinita bondade Dele, pelo que se pode pedir e ganhar constantemente o perdão.

No fundo, é o sujeito, na sua totalidade, englobando o seu inconsciente, também, que escapa, e cada vez mais o vivente não se compromete seriamente com o resgate de si mesmo. É como se deslizasse e nada lhe dissesse respeito.

A vergonha - aquela que se funda na consideração do outro, e de outro - é como se não fosse para mim, pois eu sou a vítima da violência e do crime do outro. Para ele, o que resta (ele é o resto ${ }^{14}$ ) é a vergonha radical atribuída pelo sistema penal.

12 Aqui vale lembrar os modelos penitenciários alburniano e filadelfiano, bem como europeu das casas de raspar, em que se mostrava claramente a exploração e a conservação de mão-de-obra. Isso, ainda hoje, guarda nítida referência ao sistema penal quando se refere ao instituto da remição de pena, existente na Lei de Execução penal, antecedido pela disposição expressa de que o trabalho do preso é obrigatório.

${ }^{13}$ Esta ideia de utilidade, como força produtiva da manutenção do poder e concentração de riquezas, é ressaltada por Juarez Cirino dos Santos, ao tratar da desigualdade social frente ao Direito Penal, ponderando que há evidente distinção na proteção dos participantes nestas relações de produção e de circulação materiais da vida social, fazendo alusão a uma classificação - que o sistema comprova por si - e que assim se apresenta: a) os seres humanos, tratados como sujeitos eis que titulares dos bens que se integram à produção e à circulação de bens; b) os objetos, que são a força produtiva assalariada; c) os sem função, enfim como os que estão fora de todo este processo; se os primeiros como sujeitos e os segundos como objeto recebem proteção (mesmo que os seres humanos, delas gozem com evidente vantagem), os últimos tendem a ser eliminados, inclusive, pela própria violência institucional (2007, p. 11).

${ }^{14}$ A ideia de que o outro é animal (v. AGAMBEN, 2002). Zygmunt Bauman ao referir a figura de Agamben assenta que "a vida de um homo sacer é desprovida de valor, seja na perspectiva humana ou na divina. Matar um 
O esgarçamento dos controles informais e a falta de vergonha estão identificados, também, nas palavras de Contardo Calligaris (2008, p. 179-182) pela demonstração de que a sociedade apresenta um déficit moral e a malandragem aparece reiteradamente como substantivo e não mais como adjetivo. Na distinção entre culpa e vergonha acaba por prevalecer a ideia da culpa, pois o arrependimento - numa sociedade essencialmente católica - permitiria o erro, eis que o perdão sempre será dado por Ele, e o sujeito segue pecando e sendo perdoado (dado o seu arrependimento), dando ensejo a um dispositivo extraordinariamente permissivo; enquanto que a vergonha seria um fator inibidor.

Em termos de vergonha, existiria uma vergonha antiga e uma moderna. Na antiga, “um ato compromete o significado de sua própria existência, quebra a integridade de seu ser" (CALLIGARIS, 2008, p. 183-186) tendo em conta a distinção entre uma vergonha oriental e ocidental, decorrentes de códigos de honra e de conduta. Na modernidade tais códigos de conduta estariam obsoletos, e o que importa é a simpatia que os outros têm em relação ao sujeito; é o olhar da consideração alheia (a importância que o eu dá para o olhar do outro). Na antiga, a indignidade é interna; na moderna, externa.

Na modernidade, surge a ideia de uma gente que é sem-vergonha (CALLIGARIS, 2008, p. 187-190). Contardo Calligaris alude a ideia de modernidade em que um grupo de pessoas ocupa um "mundo prepotente e vulgar", que esbanjam, gastam e demonstram quão maravilhosa é sua vida, plantando a ideia de que na história de vida do outro não haverá o seu status privilegiado. Já na visão de Zygmunt Baumann, são gente feita para a felicidade, não para o tédio e o enfadonho, nem para o trabalho penoso; as tarefas desgostosas e sujas são para os outros. "Em seus sonhos noturnos podem moldar-se à semelhança dos consumidores, mas é a sobrevivência física, e não a orgia consumista que lhes ocupa os dias. Está montado o palco para o encontro dos dejetos humanos com as sobras das orgias consumistas - de fato, parecem feitos uns para os outros..." (BAUMAN, 2007, p. 77).

Parece ser a sociedade do excesso e da falta. Este extrato da cultura, que é uma forma absolutamente complexa de ajustes e feitura de códigos e de símbolos, marca inegavelmente esta questão. Certo é que Contardo Calligaris excepciona a ideia de unanimidade no mundo de privilegiados esbanjadores e sem-vergonha.

$\mathrm{O}$ radicalismo desta prática irá desbordar em uma vergonha extrema e, porque não dizer, perigosa: a vergonha de ser pobre, que desborda na questão do lixo, do sujeito que se acinzenta, que "sai da moda", que sobra. Se não conseguir viver com esta vergonha

homo sacer não é um delito passível de punição, mas sua vida não pode ser tirada num sacrifício religioso. Privada da significação humana e divina que só a lei pode conferir, a vida do homo sacer é inútil. Matar um homo sacer não é crime nem sacrilégio, mas, pela mesma razão, não pode ser uma oferenda." (BAUMAN, 2005, p. 44). 
de ser pobre e cometer um crime ${ }^{15}$, ficará para ele a vergonha de ser delinquente, que será seu padecimento: a vergonha do próprio ser (CALLIGARIS, 2008, p. 191-194). ${ }^{16}$

\section{PARA SEMPRE REFUGO}

Um complexo ciclo daqui nascerá favorecendo ao sujeito uma permanente carreira delinquente, amargando os efeitos criminógenos do cárcere, que superarão o indivíduo - em verdadeira violação ao princípio da intranscendência da pena - e atingirão também suas filhas que se prostituirão e os seus filhos que se pivetizarão (CIRINO DOS SANTOS, 2007, p. 476/478), completando o destino de toda essa gente, que já morava perto ou no lixo, e que se transfere apenas do lugar que deles cuida: do aterro para a prisão.

Uma vez rejeitado, sempre rejeitado. Para um ex-presidiário sob condicional ou sursis, retornar à sociedade é quase impossível, mas é quase certo retornar à prisão (BAUMAN, 2005, p. 107).

[...] as prisões, como tantas outras instituições sociais, passaram da tarefa de reciclagem para a de depósito de lixo. (BAUMAN, 2005, p. 108).

Ainda, na perspectiva da organização da sociedade, a elite econômica, segundo Jurandir Freire (2001, p. 82-83), situa-se num mundo etéreo, que nem é a realidade grotesca na qual está inserida e nem é o mundo internacional e globalizado que desejariam estar. A efemeridade de sua situação leva-a a laborar de forma intensa - e daí sua inconsciência sob a adoção da violência branca com a qual contam - para manter essa situação, até como uma forma de conforto.

O mundo fantasma tão almejado - mas de consequências inconsequentes - é o individual, da felicidade prêt-à-porter (FREIRE, 2001, p. 82-83; BAUMAN, 2005) em que o trio sexo, drogas e cartão de crédito são os ideais perseguidos ardentemente. Esse trio leva a consequências desastrosas pela demonstração da possibilidade de "aquisição" de felicidade.

Perde-se, assim, um referencial seguro no campo ético, o que indica um recolhimento que passaria do individualismo e iria ao egocentrismo extremo, adotando ideias reacionárias e punitivas, que evitam um enfrentamento de questões que geram a violência, usando formas redutoras e empobrecidas para manter uma situação histórica

15 As estatísticas oficiais sobre crimes patrimoniais dão conta disso.

16 Ainda: Coutinho (2007, p. 137/150), ao referenciar que a sociedade sequer considerava que a retirada da dignidade daquele que está no sistema penitenciário, pudesse manter sua inteligência, usada para a revolta contra o sistema. É a falta de responsabilidade sobre si que deriva da falta de responsabilidade pelo outro (Cf. LÉVINAS, 1997; BINDER, 2004; DUSSEL, Enrique, 2002). 
de exclusão social (LÉVINAS, 1997; BINDER, 2004; DUSSEL, 2002), com vistas ao seu hedonismo (extremo oposto da alteridade).

Construir novas prisões, aumentar o número de delitos puníveis como a perda da liberdade, a política da "tolerância zero" e o estabelecimento de sentenças mais duras e mais longas podem ser medidas mais bem compreendidas como esforços para reconstruir a deficiente e vacilante indústria da remoção do lixo - sobre uma nova base, mais antenada com as novas condições do mundo globalizado. (BAUMAN, 2005, p. 108-109).

A dificuldade de eleger bons exemplos de conduta para pautar suas ações acaba por fortalecer as ideias individualistas e excludentes. ${ }^{17}$

Situados no topo da pirâmide social do país ficam perto, próximos e arraigados à estrutura do poder estatuído - na histórica outorga de autoridade e administração parental - que se contamina por seus desejos de autopreservação, levando para o espaço público o seu interesse privado. Sua atuação no espaço público pode-se dizer, não é um conluio prévio com vistas à eliminação de um segmento social, mas sim um apoderamento desse espaço, com questões estritamente individuais. Seus hábitos culturais são apolíticos, no sentido de não buscar uma solução equitativa e equânime para o todo ${ }^{18}$. Jurandir Freire trabalha com as ideias reitoras desse esforço como (i) o alheamento em relação ao outro e (ii) a irresponsabilidade em relação a si ${ }^{(2001, \text { p. } 80)}$.

$\mathrm{O}$ alheamento em relação ao outro ${ }^{19}$ serve-se da atribuição de que o outro é um ser não moral, ou seja, o outro não é semelhante a mim (não como uma ideia de moral católica), e enquanto estranho não cabe a mim seu trato e consideração (e nem a consideração dele sobre os meus atos de vergonha). A ideia da estratégia da estranheza do semelhante foi um dos pontos trabalhados na solução final dos judeus, segundo relato de Hannah Arendt (1999), onde essa prática justificava o extermínio de um ser que não era moral, não era igual a mim e não tinha face.

A importância deste ser estranho não é só no campo da subjetivação, mas também na possibilidade de que se possa reunir, com o uso do outro, mais predicados e adjetivos, e, se preciso for, fazer com que se acomode de forma dócil ou punitiva no lugar social a ele destinado (aterro ou prisão).

A acomodação dócil adota a descaracterização do ser moral, a sua inconsciência sobre si, a ideia de servidão e acolhimento de sua situação tragicamente desfavorecida como produto do acaso: a elite não tem responsabilidade pela sua condição e a miséria não pode ser modificada, portanto, deve ele reconhecer sua condição e não tentar

17 Situada em outro contexto, mas questionando a capacidade de reflexão, é a lição de Hannah Arendt, quando lembra as consequências da dificuldade de escolher exemplos para moldarmos nossas ações, asseverando que “em termos morais e até políticos, essa indiferença, embora bastante comum, é o maior perigo” (2004, p. 212).

${ }^{18}$ Aqui a visão dusseliana sobre um modelo para todos: Bauman, 2005a.

19 Aqui está fortemente a ideia de Emmanuel Lévinas sobre a perda da proximidade do próximo, a descaracterização do rosto. Também da falta de responsabilidade pelos outros, na visão dusseliana. 
deixá-la: o status quo é mantido historicamente. Os intocáveis cuidam do que é intocável (BAUMAN, 2005, p. 77).

A necessidade de reprodução da realidade social é tão arraigada como contributo ao controle social, que se inicia logo no sistema escolar que "no conjunto que vai da instrução elementar à média e à superior, reflete a estrutura vertical da sociedade e contribui para criá-la e para conservá-la através de mecanismos de seleção, discriminação e marginalização" (BARATTA, 2002, p. 172), que controlam a insubordinação.

A constatação que segue - na desenfreada busca pela manutenção do status quo - é que os produtos do caso fortuito (pessoas-não-humanas) podem ser controlados, através de uma acomodação punitiva, que se desenvolve nas formas de criminalização primária e secundária ${ }^{20}$, caso eles tentem desempenhar papéis diferentes daqueles que a sorte lhes reservou, ou mostrem-se descontentes com sua situação social.

A prevalência nesse processo de orientação seletiva, marginalizadora e criminalizadora parecem ser dos powerfull, conforme já atentara Nilo Batista, quando lembra que historicamente as elites, em sistemas capitalistas, correm ao direito penal para "duas operações essenciais: $1^{\mathrm{a}}$ garantir a mão-de-obra; $2^{\mathrm{a}}$ impedir a cessão do trabalho", e adiante exemplifica sua proposta lembrando que:

Essa punição se apresenta implacavelmente sempre que os pobres, negros ou quaisquer outros marginalizados vivem a conjuntura de serem acusados da prática de crimes interindividuais (furtos, lesões corporais, homicídios, estupros etc.). Porém essa punição permeia principalmente o uso estrutural do sistema penal para garantir a equação econômica. Os brasileiros pobres conhecem bem isso. Ou são presos por vadiagem, ou arranjam emprego e desfrutem do salário mínimo (punidos ou mal pagos). Depois que já estão trabalhando, nada de greves para discutir o salário, porque a polícia prende e arrebenta (punidos e mal pagos) (1990, p. 39).

A criminalização abstrata ou primária já sabe quem deseja atingir, e a secundária, segue a mesma orientação seletiva em três espectros: (i) criminalizante ${ }^{21}$, vitimizante $^{22}$

${ }^{20}$ Expressões referenciadas por Baratta (2002) e por Zaffaroni; Batista et al. (2003). Nessas obras os autores trabalham, dentre outros temas, com o referencial das relações econômicas em situações de domínio do capitalismo e do liberalismo para questionar a legitimidade da intervenção do Direito Penal. A mesma crítica sobre a relação capital x trabalho, em: Cirino dos Santos (2006).

${ }^{21}$ Zaffaroni; Batista et al. indicam que isso pode ser feito através de (i) estereótipos, que são aqueles que têm "uma imagem pública do delinqüente com componentes de classe social, étnicos, etários, de gênero e estéticos" (2003, p. 46); (ii) comportamentos grotescos em virtude de atos de brutalidade singular que não se pode ignorar e (iii) devido à falta de cobertura (em que se vêem pessoas que, de modo excepcional, enfrentam a punição porque "levou a pior parte em uma luta de poder hegemônica e sofreu por isso uma ruptura na vulnerabilidade" (2003, p. 49), quanto a este último deve se refletir sobre o grau de inconsciência quando a sociedade se depara com a criminalização de um personagem que não se mostra como um cliente convencional do direito penal, especificamente o que acontece com os delitos econômicos, destinados, quase que na totalidade, para pessoas que ocupam posições de destaque em diversas estruturas de poder público e privado.

${ }^{22}$ Onde há uma seleção através da situação mais vulnerável de determinadas pessoas que se apresentam como vítimas, até mesmo polarizando a segurança pública para as elites. Reforça-se a proposta de Enrique Dussel (2002, p. 565). 
e policizante ${ }^{23}$, as quais buscam garantir o adestramento do inimigo, figura identificada, nesse caso, no substrato social menos favorecido: refugo natural do processo de produção.

A outra ideia com que trabalha Jurandir Freire, como já mencionado, é a irresponsabilidade em relação a si, que se caracteriza pelo que se poderia denominar de efeito colateral do alheamento em relação ao outro, decorrente da ideia de que os seus valores devem estar sedimentados dentro da sociedade como regras de conduta.

\section{FEITOS UNS PARA OS OUTROS}

Seria, portanto, uma forma de insurgência - normalmente representada por uma violência criminosa - dos menos favorecidos, gerando o flagelo da violência: se o ethos da elite prega uma desimportância em relação ao marginalizado, o ethos do marginalizado também se pauta por essa indiferença.

Os desfavorecidos ao aprenderem bem a lição sobre a sua situação fortuita, em que foram lançados à própria sorte, retiram da elite, também, a ideia de sujeito moral. Identificam essa elite como alguém que acumulou riqueza, indevidamente, e que por isso pode lhes ser subtraída, mediante atos de horror24: atos toscos e grotescos que permeiam o cotidiano de sua condição marginalizada, como homicídios, sequestros, tráfico etc.

Jacinto Nelson de Miranda Coutinho (2007, p. 145) lembra as palavras de Marcola (o Chefe do PCC) que dizem tudo: nós não temos medo de vocês, mas vocês têm de nós. ${ }^{25}$

"Em tais circunstâncias, nenhuma linha que separe o 'refugo' do 'produto útil' tende a se manter incontestada, e nenhuma sentença que condene a viver num depósito de lixo tende a se sustentar por muito tempo sem que haja uma oposição fazendo o possível para derrubá-la ou revertê-la." (BAUMAN, 2005, p. 111).

E aí se reforçam as incongruências desses mundos (FREIRE, 2001, p. 83-84): de um lado desemprego, fome, corrupção, mortes, estupros etc.; de outro, sexualidade feliz, pornografia, encontros privilegiados, shoppings centers, hipnóticos, drogas etc.,

23 A escolha passa a ser feita pela polícia, pelo Ministério Público, pelo Poder Judiciário e outros atos reais de poder (para superação da falta da lei simbólica) que tem de escolher entre a inoperância total e a tentativa de demonstrar sua eficácia, até para justificar sua existência.

${ }^{24}$ Um alastramento dessa situação fica mais eficaz em um Direito Penal subterrâneo que se vê em campos de concentração e de refugiados, em incitação à xenofobia, em controle econômico, em atuações dos sub-Estados e de estruturas de poder paralelas, como os comandos em penitenciárias e facções criminosas. (Cf. BAUMAN, 2005).

${ }^{25}$ Na sequência, ainda analisa, a ideia de Contardo Calligaris, nesta alusão a "Marcola", então Chefe do Primeiro Comando da Capital (PCC), referindo a questão da prisão que poderá fomentar a criação de um sujeito preso, pensante e revoltado, que levará a atos de barbárie. 
decorrentes de um antagonismo impensado e imoral que contrapõe um "eu infeliz" com o "outro inexistente".

Apresenta-se assim - embora pensando a elite econômica estar num mundo etéreo - a estrutura social segmentada em castas, cuja ideia darwinista está presente na competência para sobreviver; um e outro usando de forma inconsciente a violência, separados pela linha do sistema penal.

Essa fronteira precisa da constante diligência e vigilância porque não é absolutamente uma "fronteira natural": não há montanhas altíssimas, oceanos sem fundo ou gargantas intransponíveis separando o dentro e o fora. E não é a diferença entre produtos úteis e refugo que demarca a divisa. Muito pelo contrário, é a divisa que prediz - literalmente, invoca - a diferença entre eles: a diferença entre o admitido e o rejeitado, entre o incluído e o excluído (BAUMAN, 2005, p. 39).

A sociedade, que desconhece uma experiência de tolerância e fraternidade, precisa de alguém ou de algo para fazer o serviço de limpeza, atribuindo ao sistema penal o poder de higienização ${ }^{26}$ e especialmente de manutenção do processo histórico de exclusão, legitimando cada vez mais os processos de executivização do sistema penal e de letalização de suspeitos, por milícias, grupos de extermínio e vigilantes privados, ou mesmo pela atuação individual e cotidiana.

Odiamos essas pessoas porque sentimos que aquilo que elas sofrem diante de nossos olhos bem pode se mostrar, e muito em breve, um ensaio de nosso próprio destino. Fazendo o possível para afastá-las de nossas vistas - recolhê-las, trancá-las em acampamentos, deportá-las -, pretendemos exorcizar esse espectro. (BAUMAN, 2005, p. 158)

O caso brasileiro - assim como o de seus vizinhos - é um exemplo do uso da violência como meio de manutenção da situação entendida como privilegiada ${ }^{27}$ da elite econômica, que incorpora - mesmo de forma inconsciente - o ethos da violência, e parece não ter, de fato, consciência do que faz, mas pode ter do por que faz. ${ }^{28}$ Isso é possível porque retirei do outro seu rosto ${ }^{29}$ (LÉVINAS, 1997, p. 237), sua humanidade, seu eu.

${ }^{26}$ Zygmunt Bauman trabalha muito com a ideia de que a remoção do lixo evoca a experiência da ordem e da limpeza, da organização. É separar os outsiders. (BAUMAN, 2005, especialmente: p. 40/45).

${ }^{27}$ Jurandir Freire aborda o tema "a partir da visão que o indivíduo de elite tem de seu destino socioindividual” (2001, p. 80). Também Calligaris (2008, p. 187-190); Coutinho (2007, p. 137/150).

${ }^{28}$ A questão do distanciamento do consciente sobre o agir violento é indicada por Hannah Arendt na obra Eichmann em Jerusalém - um relato sobre a banalidade do mal, 1999, em que trabalha com a infeliz constatação de que a faculdade de julgar nem sempre está presente no ser humano.

${ }^{29}$ Lévinas trabalha com a ideia da epifania e da significância do rosto: "despertar para o outro homem na sua identidade indiscernível para o saber, aproximação do primeiro, vindo em sua proximidade de próximo, comércio com ele, irredutível experiência. Antes de toda expressão particular de outrem - e sob toda expressão que, já postura dada a si, protege - nudez e carência da expressão com tal. Exposição à queima-roupa, extradição de investido e cercado - cerca antes de toda caça e toda batida. Rosto como a própria mortalidade do outro 
Fatores históricos no caso brasileiro - também recorrentes em outros países - são reforços para esse ethos, desprovido de alteridade, que precisa mudar, podendo-se citar, dentre tantos, a colonização, a ideia escravocrata, a cultura servil, a concentração de renda, os conflitos de interesse, que permeiam o pensamento de uma dominante elite econômica ou daqueles que concentram o poder hegemônico.

Há, com alguns traços modificativos, uma ideia repetida de que o poder deve se concentrar em poucos, os quais detêm a parcela interessante da renda, e assim deve ser mantida a história de exclusão-inclusão, pelo controle do exercício do poder de polícia e do sistema penal.

\section{O FIM É O COMEÇO: RECICLAR}

Nem o medo de que o sistema devore os seus próprios filhos ou a si mesmo parece conseguir frear o desejo punitivo, talvez por uma certeza histórica de que o sistema seleciona apenas os outros. Resgatar a alteridade com a configuração do outro como igual a mim, na sua diferença, deve fazer o rasgo desta história; colocando uma trava na engrenagem para quebrar o ciclo vicioso que perpetua a exclusão social, operada, também, pelo sistema penal.

Resgatar $^{30}$ a alteridade do outro e não mais pensá-lo como um refugo a ser depositado em definitivo, significa resgatá-lo com a ideia de solidariedade, para que possa tê-lo como igual e propor a liberdade ${ }^{31}$, mesmo para mim.

homem." Diversas passagens na obra de Hannah Arendt lembram os artifícios usados pelo Regime para tirar o outro, de apagar o rosto do outro: acinzentando o outro, que deixa de ser um sujeito moral. (Em especial: Eichmann em Jerusalém - um relato sobre a banalidade do mal, 1999).

${ }^{30}$ Aqui é imprescindível ter em mente o processo real de absoluta exclusão em que se encontra a sociedade brasileira, como seus demais vizinhos latino-americanos, que exigem a solidariedade: "Aquele que opera éticocriticamente deve (está obrigado a) libertar a vítima, como participante (por 'situação' ou por 'posição' - diria Gramsci) da própria comunidade a que pertence a vítima, por meio de a) uma transformação factível dos momentos que causam a negatividade material (impedem algum aspecto da reprodução da vida) ou discursivo-formal (alguma simetria ou exclusão da participação) da vítima; b) a construção, através de mediações com factibilidade estratégicoinstrumental críticas, de novas normas, ações, microestruturas, instituições ou até sistemas completos de eticidade onde essas vítimas possam viver, sendo participantes iguais e plenos. Tratar-se-ia - como já repetimos com frequência - de um desenvolvimento, de um 'progresso qualitativo' histórico. Esta obrigação tem pretensão de universalidade; quer dizer, vale para todo ato e toda situação humana. O interesse libertador (que se funda na ideia regulativa de uma sociedade sem vítimas - embora se saiba de sua impossibilidade empírica - e, concretamente - e isto, sim, é empiricamente possível -, sem este tipo histórico de vítima, pela qual cada um é empiricamente responsável, e por isso é preciso lutar para que seja possível a sua libertação) move pulsionalmente e abre o horizonte desta obrigação levada a cabo pela razão libertadora (razão ético-crítica prático-material, discursiva consensual e estratégicoinstrumental." (Dussel, 2002, p. 565).

31 Significa resgatar o meu próprio desejo de liberdade: Dussel (2002, p. 544 e ss.), ao discutir o princípio libertação. 
Mas a transição do tempo e do lugar, de pessoas em busca de algo, como diáspora, como busca ou como fuga, demonstra uma sempre vontade de ir além. Ir além, não pode ser pensado como a liberdade última; o gozo e a vontade de liberdade não são ilimitados, porque pressupõem o igual, em face de quem não se pode tudo. Ele também é livre.

O que equilibra a liberdade e a igualdade? Não uma relação vertical de competição, mas sim uma relação horizontal de solidariedade e fraternidade.

A vida cotidiana exige compartir, tomar decisões e assumir posicionamentos, buscar as memórias comuns e criar histórias que poderão ser contadas. Mas é preciso que possa existir alguém para ouvi-las. Melhor que não estejam presas; melhor que não estejamos presos. Quem sabe livres para sair de Leônia rumo à Aglaura.

Diga-me quais são seus sonhos $e$ eu lhe direi do que mais sente falta $e$ quais são seus temores. (BAUMAN, 2005, p. 157).

\section{REFERÊNCIAS}

AGAMBEN, Giorgio. Homo sacer: $O$ poder soberano e a vida nua, I. Belo Horizonte: Ed. UFMG, 2002. Título Original: Homo sacer: il potere sovrano e la nuda vita I.

ARENDT, Hannah. Origens do Totalitarismo - Anti-Semitismo, Imperialismo, Totalitarismo. São Paulo: Companhia das Letras, 1989. Título original: The Origins of Totalitarism - Anti-Semitism, Imperialism, Totalitarism. New York: Ed. Harvest - HJB Book, 1975. Trad. Brasileira de Roberto Barroso.

ARENDT, Hannah. Eichmann em Jerusalém - Um relato sobre a banalidade do mal. São Paulo: Companhia das Letras. 1999. Título original: Eichmann in Jerusalem - A Report of the Banality of Evil. New York: Penguin Books, 1977. Trad. Brasileira de José Rubens Siqueira.

ARENDT, Hannah. Responsabilidade e Julgamento. Introdução à edição brasileira Bethânia Assy. São Paulo: Companhia das Letras, 2004. Título original: Responsability and Judgment. Edited and with an introduction by Jerome Kohn. New York: Schocken Books, 2003. Trad. Brasileira de Rosaura Maria Eichenberg.

BARATTA, Alessandro. Criminologia Crítica e Crítica do Direito Penal - Introdução à Sociologia do Direito Penal. Tradução e prefácio de Juarez Cirino dos Santos. 3. ed. Rio de Janeiro: Revan, 2002.

BATISTA, Nilo. Punidos e mal pagos: violência, justiça, segurança pública e direitos humanos no Brasil de hoje. Rio de Janeiro: Revan, 1990.

BATISTA, Nilo. Mídia e sistema penal no capitalismo tardio. Discursos Sediciosos - Crime, Direito e Sociedade. Rio de Janeiro: Revan, Ano 7, n. 12, p. 271-288. $2^{\circ}$ Semestre de 2002.

BATISTA, Vera Malaguti. O medo e o método. Discursos Sediciosos - Crime, Direito e Sociedade. Rio de Janeiro: Freitas Bastos Editora, Ano 5, n. 9 e 10, p. 187-195. $1^{\circ}$ e $2^{\circ}$ Semestres de 2000. 
BAUMAN, Zygmunt. Globalização - As Consequências humanas. Rio de Janeiro: Jorge Zahar Editor, 1999.

BAUMAN, Zygmunt. Modernidade Líquida. Rio de Janeiro: Jorge Zahar Editor, 2001.

BAUMAN, Zygmunt. Amor Líquido: sobre a fragilidade dos laços humanos. Tradução Carlos Alberto Medeiros. Rio de Janeiro: Jorge Zahar Editor, 2004. Título original: Liquid Love.

BAUMAN, Zygmunt. Vidas Desperdiçadas. Tradução Carlos Alberto Medeiros. Rio de Janeiro: Jorge Zahar Editor, 2005. Título original: Wasted lives: (modernity and its outcasts).

Bauman, Zygmunt. Em busca da Política. Rio de Janeiro: Jorge Zahar Editor, 2005.

BAUMAN, Zygmunt. Confiança e Medo na cidade. Tradução Miguel Serros Pereira. Rio de Janeiro: Jorge Zahar Editor, 2006. Título original. Trust Fear in the Cities.

BAUMAN, Zygmunt. Tempos Líquidos. Tradução Carlos Alberto Medeiros. Rio de Janeiro: Jorge Zahar Editor, 2007.

BAUMAN, Zygmunt. Medo Líquido. Rio de Janeiro: Jorge Zahar Editor, 2008.

BECK, U. La sociedad del riesgo. Hacia una nueva modernidad. Traducción de Jorge Navarro, Daniel Jiménez, e Ma Rosa Borrás. $1^{\mathrm{a}}$ edición. Barcelona: Paidós Ibérica S.A., 1998. Título original Risikogesellschaft. Auf dem Weg in eine andere Moderne.

BINDER, Alberto M. Justicia penal y estado de derecho. 2. ed. Buenos Aires: Ad hoc, 2004.

CALLIGARIS, Contardo. Culpa e Vergonha. Quinta Coluna. São Paulo: Publifolha. 2008. p. 179-182.

CALLIGARIS, Contardo. Dois Tipos de Vergonha. Quinta Coluna. São Paulo: Publifolha, 2008. p. 183-186.

CALLIGARIS, Contardo. Privilegiados Sem-Vergonha. Quinta Coluna. São Paulo: Publifolha, 2008. p. 187-190.

CALLIGARIS, Contardo. A Vergonha de Ser Pobre. Quinta Coluna. São Paulo: Publifolha, 2008. p. 191-194.

COUTINHO, Jacinto Nelson Miranda. Segurança Pública e suas políticas no Paraná. Esboço de Anteprojeto das diretrizes básicas às políticas de segurança pública ao Governo do Paraná - gestão 2003-2006.

COUTINHO, Jacinto Nelson Miranda. O gozo pela punição (em face de um estado sem recursos). Estudos Constitucionais. Rio de Janeiro: Renovar, 2007. p. 137-150.

DUSSEL, Enrique. Ética da Libertação: na idade da globalização e da exclusão. Trad. Ephrai, Ferreira Alves, Jaime A. Clasen e Lúcia M. E. Orth. 2. ed. Petrópolis: Vozes, 2002.

DUSSEL, Enrique. Filosofia da Libertação - crítica à ideologia da exclusão. Trad. Georges Massaiat. São Paulo: Paulus, 2005.

ELIAS, Norbert. Os Estabelecidos e os Outsiders: sociologia das relações de poder a partir de uma pequena comunidade. Trad. Vera Ribeiro. Rio de Janeiro: Jorge Zahar Editor, 2000.

FREIRE, Jurandir. O Desafio Ético. 2001. 3. ed. Rio de Janeiro: Garamond, 2001.

KARAM, Maria Lucia. Segurança Pública e processo de democratização. Discursos Sediciosos Crime, Direito e Sociedade. Rio de Janeiro: Freitas Bastos, Ano 3, n. 5 e 6, p. 169-192. $1 .^{\circ}$ e $2 .^{\circ}$ semestres de 1998. 
LÉVINAS, Emmanuel. Entre nós: ensaios sobre a alteridade. Petrópolis: Vozes, 1997. Título Original: Essais sur le penser-àl ' autre.

LÓTMAN, Iúri M. Semiótica dos conceitos de "vergonha" e do "medo". Ensaios de Semiótica Soviética. Coleção Horizonte. Lisboa: Livros Horizonte, 1981. p. 237-240. Tradução Victória Navas e Salvato Teles de Menezes.

MELOSSI, Dario; PAVARINI, Massimo. Cárcere e Fábrica. As origens do sistema penitenciário (séculos XVI - XIX). Rio de Janeiro: Revan: ICC, 2006.

SANTOS, Juarez Cirino dos. A Criminologia Radical. 2. ed. Curitiba: Lumen Juris: ICPC, 2006.

SANTOS, Juarez Cirino dos. Direito Penal. 2. ed. Curitiba: ICPC; Lumen Juris. 2007.

SIlva SancheZ, Jesús-María. A Expansão do Direito Penal - Aspectos da Política

Criminal nas Sociedades Pós-industriais. Série "Ciências Criminais do Século XXI - v. 11. São Paulo: Revista dos Tribunais, 2002. Título original: La expansión del derecho penal: aspectos de la política criminal en las sociedades postindustriales. Tradução de Luiz Otavio de Oliveira Rocha.

YOUNG, Jock. A sociedade excludente: exclusão social, criminalidade e difrença na modernidade recente. Trad. Renato Aguiar. Rio de Janeiro: Revan: ICC, 2002.

WAICQUANT, Löic. Os condenados da cidade: estudos sobre marginalidade avançada. 2. ed. Trad. João Roberto Martins Filho et al. Rio de Janeiro: Revan; FASE, 2005.

ZAFFARONI, Eugenio Raúl. O Inimigo no Direito Penal. Tradução de Sérgio Lamarão. Coleção Pensamento Criminológico - v. 14. Rio de Janeiro: Revan: ICC, 2007.

ZAFFARONI, Eugenio Raúl. ALAGIA, Raul Alejandro; SLOKAR, Alejandro e BATISTA, Nilo.

Direito Penal Brasileiro - I. Rio de Janeiro: Revan, 2003. 